CASE REPORTS

\title{
Reversible acute myocardial injury following air bag deployment
}

\author{
D V Nagarajan, M Wilde, M Papouchado
}

Emerg Med J 2005;22:382-383. doi: 10.1136/emj.2003.010942

This case report is about a 62 year old woman who was involved in an accident while driving her car, during which the driver side air bag deployed. She experienced intense anterior chest pain that radiated to her left arm after the accident, but was otherwise well; there was no significant medical history. An electrocardiogram done one and half hours after admission revealed $1 \mathrm{~mm}$ ST segment elevation in leads V2 and V3 and troponin 1 level was raised. She underwent cardiac catheterisation but three months after the accident both ECG and echocardiographic studies were normal. It is suggested that she underwent cardiac contusion rather than a myocardial infarction.

$\mathrm{D}$ river side air bags are meant to provide protection during the rapid deceleration that occurs after accidents, particularly in those involving frontal collision. ${ }^{1}$ These have been shown to decrease the morbidity and mortality associated with high speed injuries when used in conjunction with lap and shoulder belts. ${ }^{2-4}$ Air bags inflate at a rate of $6 \mathrm{l} / \mathrm{ms}$, generating a velocity that has been measured at $157.7-339.6 \mathrm{~km} / \mathrm{h}(98-211 \mathrm{miles} / \mathrm{h}$; average $21.7 \mathrm{~km} / \mathrm{h}$ or $144 \mathrm{miles} / \mathrm{h}){ }^{5}$

In some instances air bags have been implicated as the direct cause of the injuries, most of which are usually minor. However, three major cardiovascular problems, aortic transection, ${ }^{67}$ tricuspid valve injury, ${ }^{8}$ and delayed cardiac rupture, ${ }^{9}$ have been reported. We present a patient who experienced reversible myocardial injury following air bag deployment.

\section{CASE REPORT}

A 62 year old lady was driving at a speed of about $32 \mathrm{~km} / \mathrm{h}$ (20 miles/h) when her car was hit on the side by another car travelling at about the same speed (the patient could not recollect which side it was). She was wearing her seat belt, and her air bag deployed almost instantaneously. She felt a crushing anterior chest pain radiating to her left arm immediately after the accident, but denied loss of consciousness, shortness of breath, or palpitations. She had no significant past medical history, was not currently on any medication, and had never smoked. There was no significant family history of ischaemic heart disease.

On examination she was well oriented with a Glasgow Coma Scale score of 15/15. She was haemodynamically stable with a pulse of 96/min and blood pressure $40 / 80 \mathrm{~mm} \mathrm{Hg}$. Jugular venous pressure was not elevated and auscultation of her heart revealed normal heart sounds with no murmurs. The anterior chest wall was tender on palpation. Her respiratory rate was $15 / \mathrm{min}$ with $98 \%$ oxygen saturations on room air. Auscultation of the chest revealed no abnormalities. Abdomen and nervous system examinations were essentially normal.
A chest $x$ ray revealed normal cardiac contours, clear lung fields, and no bony injuries. The initial electrocardiogram (ECG) revealed ventricular bigemini but no other abnormality (fig 1). Another ECG, one and half hours after admission revealed $1 \mathrm{~mm}$ ST segment elevation in leads V2 and V3 (fig 2). Troponin I (TnI) level, measured six hours after admission, was elevated at $23.9 \mathrm{ng} / \mathrm{l}$ (normal<0.3 ng/l). Echocardiogram recorded within 12 hours of the accident revealed akinesia of the mid-septum and apex with mild left ventricular impairment but no pericardial effusion. We did not consider thrombolysis due to preceding history of trauma and the risk of cardiac tamponade. Her symptoms were controlled with opioid analgesia, and she was started on aspirin, atenolol, and ramipril.

A repeat ECG 36 hours after the accident revealed T wave inversion in the anterolateral leads (fig 3). She underwent cardiac catheterisation one week after admission. The ventriculogram confirmed mild anterior left ventricular impairment; selective coronary arteriography revealed normal coronary arteries. She was discharged on an angiotensin converting enzyme inhibitor and $\beta$-blocker. She was symptom free when seen in clinic three months later. An ECG at that time revealed no evidence of previous anterior myocardial injury (fig 4). An echocardiogram six months following the accident was normal with no evidence of wall motion abnormality. She remained well and symptom free 12 months after the accident, with normal ECG.

\section{DISCUSSION}

There have been previous reports of acute myocardial infarction following blunt chest wall trauma, specially in association with sternal or rib fractures, ${ }^{10}{ }^{11}$ but acute reversible myocardial injury following air bag deployment has not been reported.

In our patient, a diagnosis of acute anterior myocardial infarction was made on the basis of the ECG changes, elevated TNI and left ventricular changes on echocardiography and left ventriculography. Interestingly, she had no rib fractures and selective coronary arteriography revealed

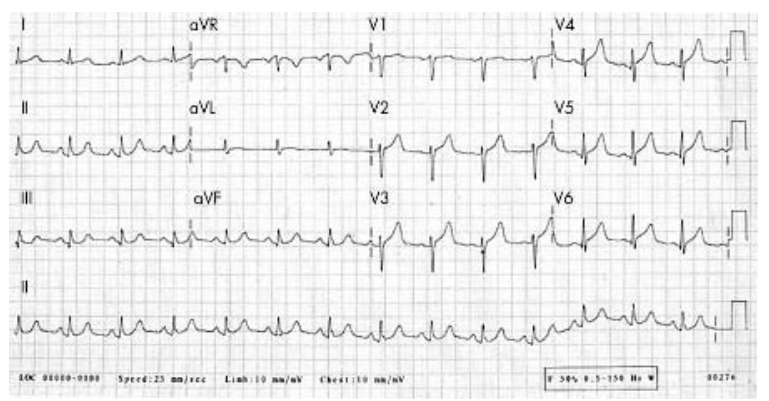

Figure 1 Initial electrocardiogram of a 62 year old woman involved in a car accident showing ventricular bigemini. 


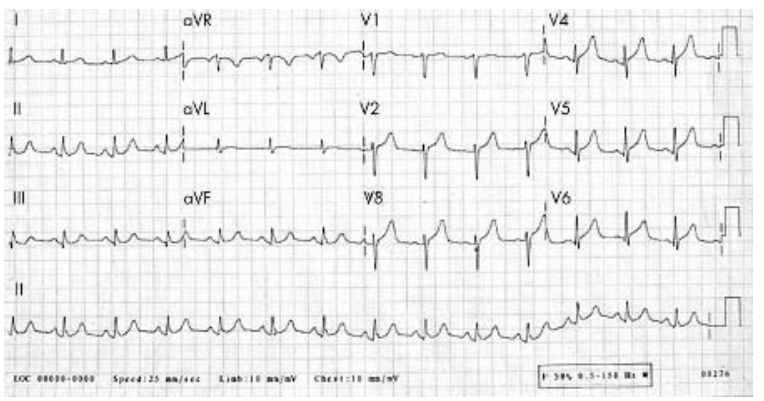

Figure 2 Electrocardiogram done one and a half hours after admission showing ST segment elevation in leads V2 and V3.

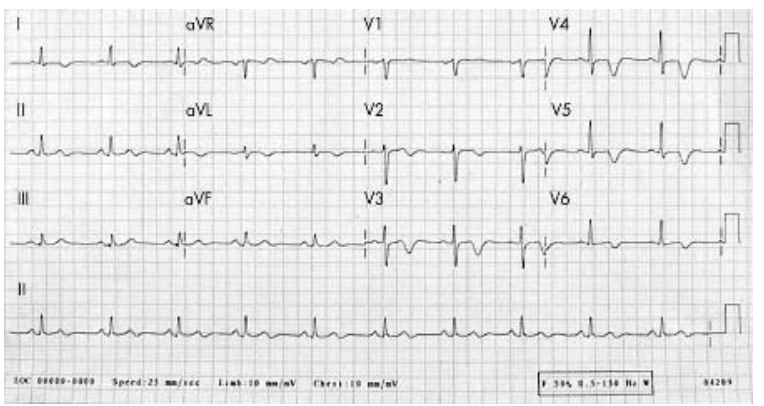

Figure 3 Electrocardiogram done 36 hours after admission showing T wave inversion in the anterolateral leads.

normal coronary arteries. However, two normal ECGs (at three and 12 months) and a normal echocardiogram six months following the accident led us to revise our initial diagnosis and suggest that she underwent cardiac contusion rather than a myocardial infarction.

Even though we diagnosed acute myocardial infarction at the time of admission, we felt the patient was not suitable for thrombolysis for three reasons. Firstly, her ECG on admission did not fulfil the criteria for thrombolysis. Secondly, any cardiac damage which she suffered would have been due to transient occlusion of the left anterior coronary artery caused by chest trauma, not by occlusion of the artery by plaque rupture followed by thrombus formation on the denuded plaque. Therefore there was no reason to suppose that she had occlusive thrombus in the coronary artery and consequently no reason to suppose that she would benefit from thrombolysis. Lastly, given the fact that she had experienced chest trauma, even though there were no rib fractures, thrombolysis could have led to haemorrhage into thoracic structures such as the pleural cavity and/or the pericardium with potentially grave consequences.

The current case highlights the facts that (a) myocardial injury can occur even in the absence of rib fractures or chest wall injury as has previously been reported ${ }^{10}$ and $(b)$ the diagnosis of myocardial infarction should be made with

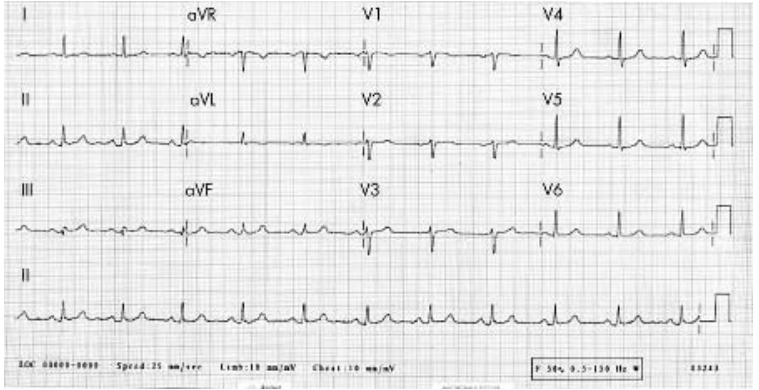

Figure 4 Electrocardiogram three months after accident.

extreme caution in cases involving chest wall trauma including air bag injuries as it is difficult to differentiate it from myocardial contusion. These patients should therefore have a coronary angiogram to determine the coronary anatomy. In the presence of normal coronary arteries, this should be followed up with repeat investigations to assess the extent of myocardial damage because ECG changes and left ventricular wall abnormalities seen on echocardiography may reverse with time.

\section{Authors' affiliations}

D V Nagarajan, Stepping Hill Hospital, Stockport, Cheshire, UK

M Wilde, M Papouchado, Frenchay Hospital, Bristol, UK

Competing interests: none declared

Correspondence to: D V Nagarajan, Queen's Medical Centre, Nottingham, NG7 2UH, UK; darbhamulla@aol.com

Accepted for publication 13 February 2004

Patient consent was obtained

\section{REFERENCES}

1 Braver ER, Ferguson SA, Greene MA, et al. Reductions in death in frontal crashes among right front passengers in vehicles equipped with passenger airbags. JAMA 1997;278:1437-9.

2 Barry S, Ginpil S, O'Neill TJ. The effectiveness of airbags. Accid Anal Prev 1999:31:781-7.

3 Foster JD, Thind IS, Fuller J, et al. Automobile accidents - seat belts and air bags. NJ Med 1986;83:715-20.

4 Evans L. Restraint effectiveness, occupant ejection from cars, and fatality reductions. Accid Anal Prev 1990;22:167-75.

5 National Highway Traffic Safety Administration. Air bag deployment characteristics. Springfield, VA: National Technical Information Service, 1992.

6 DeGuzman BJ, Morgan AS, Pharr WF. Aortic transection following airbag deployment. N Engl J Med 1997;337:573-4.

7 Dunn JA, Williams MG. Occult ascending aortic rupture in the presence of an airbag. Ann Thorac Surg 1996;62:577-8.

8 Sharma OP, Mousett XR. Review of tricuspid valve injury after airbag deployment: presentation of a case and discussion of mechanism of injury. J Trauma 2000:48:152-6.

9 Lancaster $\mathrm{GI}$, DeFrance $\mathrm{JH}$, Borruso $\mathrm{HH}$. Airbag associated rupture of the right atrium. N Engl J Med 1983;328:358.

10 Vasudevan AR, Kabinoff GS, Keltz TN, et al. Blunt chest trauma producing myocardial infarction in a rugby player. Lancet 2003;362:370.

11 Ginzburg E, Digert J, Parra-Davila E, et al. Coronary artery stenting for occlusive dissection after blunt chest trauma. J Trauma 1998;45:157-61. 


\section{The reawakening of a sleeping little giant}

\section{R Goddard}

This case report and literature review highlights the classical signs and symptoms of herpes zoster infection involving the trigeminal nerve. Incorrect diagnosis leads to delay in providing effective treatment and could result in failure to identify potentially hazardous ocular complications and to prevent chronic post-herpetic pain.

t

t is likely that herpes zoster will become more prevalent as the population ages. It is therefore important that all physicians, regardless of their specialty, be aware of this "classical" disease. It is advisable that all physicians examine the patients with anatomy in mind. In this case, intra-oral examination clinched the diagnosed. The oral cavity should not be considered as the sole domain of dentists.

Herpes zoster is rarely seen in the acute setting of the accident and emergency department, especially when it involves the trigeminal nerve. Varicella-zoster virus causes chickenpox (varicella). This is followed by a period of latency in cranial nerve and dorsal root ganglia. It can reactivate many years later to produce shingles (zoster) and postherpetic neuralgia. It is therefore a disease that is familiar to those specialist clinicians (paediatricians and geriatricians) who encounter the disease as chicken pox in childhood and shingles in the elderly. Other clinicians familiar with this virus include those who deal directly with its complications, such as dentists, oral physicians, and ophthalmologists. A reemergence of the disease demands revision by generalist medical and surgical clinicians.

\section{CASE REPORT}

A general practitioner was called to make a home visit to an 89 year old man who developed facial swelling that caused him to "take to his bed." The GP diagnosed a facial infection involving the lower eyelid. Admission was sought at the local hospital on the grounds that facial cellulitis was present requiring intravenous antibiotics. The GP was encouraged to transfer the patient to a hospital where maxillo-facial services were available, but this option was declined as the patient's spouse was elderly and would find it difficult to visit. The patient was thus admitted to his nearest hospital under the care of the surgical team, despite the lack of maxillo-facial services.

On presentation to the A\&E department, the patient complained of headache, difficulty in swallowing, and facial/eye swelling. He reported that he had been well up to three days before, when he noticed the presence of mouth ulcers. Pain ensued soon afterwards. This was sharp and constant in nature, sited in the medial aspect of his left cheek and radiating to the left supraorbital region. He complained of brown-yellowish slime in his mouth. He also developed rhinorrhoea and ulcerative lesions on the left cheek.

The patient had a past medical history typical for a man of his age, with a previous myocardial infarct and a cerebrovascular accident. He was a non-smoker and had no overt immunodeficiency disorder.

Significant examination findings were confined to the maxillo-facial region. He had an erythematous left cheek with what appeared to be multiple herpetiform crusted lesions. There was a thick white mucus discharge from the left eye. Intraoral examination showed a greyish slough covering only the left primary and secondary palate (fig l). The patient was edentulous. His respiratory system was free of clinical signs. He had a normal white cell count and was apyrexial on admission and throughout his hospital course.

Herpes-zoster infection of the trigeminal nerve was diagnosed and the patient was transferred to the care of general physicians for further management. At this point the possibility of a dental abscess or mumps was considered by junior staff on the medical firm. He was started on a course of oral flucloxacillin, metronidazole mouthwash, and intravenous benzyl penicillin. Aciclovir was not started until the following day. The antibacterial agents were discontinued after three days. The patient's recovery was somewhat delayed owing to poor mobility and the development of a short bout of diarrhoea and vomiting. After five days in hospital he was discharged home with no further prescription for aciclovir.

\section{DISCUSSION}

This case appeared to present in a classical way yet still raised diagnostic difficulties in the unwary physician, leading to delayed implementation of appropriate treatment. Physicians need to be mindful of the key diagnostic features of the reemerging dormant disease.

Herpes-zoster is very common, especially in the elderly. The annual incidence of latent herpes-zoster, which is approximately $1 / 1000$ before the age of 20 , increases five to 10 -fold (to 4.5 to $11 / 1000$ ) after 80 . Among adults over the age of 70 with acute herpes-zoster, treatment reduces the incidence of persisting pain to an estimated $50 \%$, compared with up to $70 \%$ without treatment. Approximately half the patients over 70 with herpes-zoster report pain lasting more than one year. ${ }^{1}$

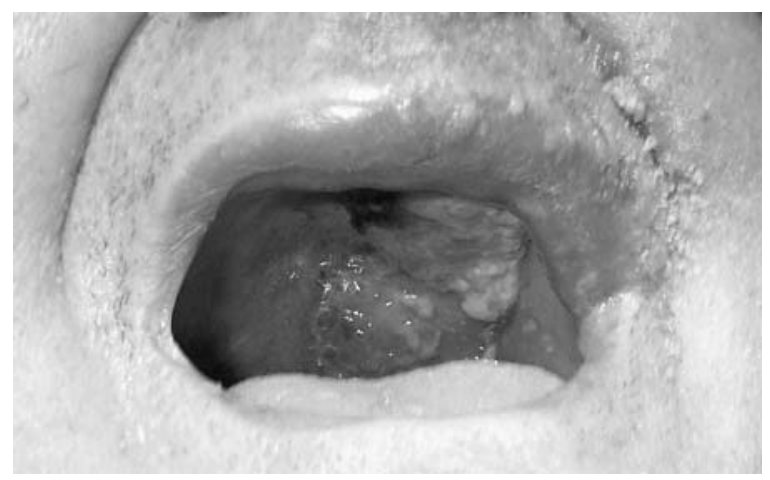

Figure 1 The appearance of the mouth and palate in the patient. 
The lifetime risk of shingles is estimated at $20 \%$ and the risk of a second attack is less than $5 \%{ }^{2}$

Herpes-zoster affects the sexes equally and its commonest symptom is pain. Patients often get a feeling of helplessness and depression and may have flu-like symptoms. A prodromal phase may include itching and paraesthesiae. Other symptoms include insomnia, limitation of movement, and post-herpetic neuralgia (pain after the cessation of the rash). The most commonly affected dermatomes are the thoracic $(45 \%)$, cervical $(23 \%)$, and trigeminal (15\%). It may affect one or more dermatomes at a time. Secondary bacterial infection may occur but rarely causes intraoral pus in an edentulous mouth.

There are a many serious complications ${ }^{3}$ which can affect the central nervous system (for example, myelitis, large and small vessel encephalitis, ventriculitis) and the peripheral nervous system (Guillain-Barré syndrome/postinfectious polyneuritis). Non-neurological complications may result from neuronal or haematological spread, especially in immunocompromised individuals, such as the elderly. These include visceral spread causing hepatitis, pneumonitis, and ophthalmic shingles. Approximately $50 \%$ of patients with herpes-zoster involving the first division of the trigeminal nerve will have ocular complications, some of which may threaten the sight. The morbidity and mortality resulting from this disease are also reflected in increased rates of hospital admission, case fatality ratios, and the incidence of cases of post-herpetic neuralgia. All these have been shown to increase markedly with the age of the patient. In a study done in Tayside it was found that most admissions resulted from involvement of the trigeminal nerve. ${ }^{4}$ The duration of hospital admission ranged from 1 to 70 days, with a median stay of 11 days. It has been estimated that it costs $£ 47.6 \mathrm{~m}$ annually to treat herpes-zoster. There is an estimated loss of 20000 quality of life years annually in England and Wales from this disease. There is therefore a very high human as well as financial cost of neglecting its prevention and treatment.

Potential strategies for the management of herpes-zoster are based, as for any other disease, on prevention (including vaccination), treatment, and follow up.

\section{Prevention}

Edmunds et al suggest that varicella vaccination is a "double edged sword". ${ }^{5}$ They concluded that vaccination of the elderly is expected to be cost-effective under most situations. On the other hand, in further paper from the same group ${ }^{6}$ it was suggested that, although vaccination results in high initial protection, full protection is lost relatively rapidly (3\% per year). It was also stated that once total protection has waned, there is a high probability of developing breakthrough infection if exposed to varicella $(73 \%$ of the probability in the unvaccinated susceptible individuals).

The varicella-zoster virus Oka strain vaccine is currently recommended by the Advisory Committee on Immunisation Practices for universal childhood vaccination in the USA. ${ }^{7}$ This vaccine increases cytotoxic lymphocyte responses specific for varicella-zoster virus in seropositive elderly people. ${ }^{9}$ There is doubt whether vaccine induced immune enhancement will reduce the incidence or severity of herpes zoster in the elderly. It appears evident that we have a hung jury on whether mass vaccination of the elderly is indicated at present.

\section{Treatment}

Early diagnosis and prompt treatment of the disease in the prodromal phase by the use of antiviral agents should probably be the mainstay of its management. The aim of this treatment is to accelerate healing, limit the severity and duration of acute and subsequent chronic pain, and reduce complications. The adjunctive use of corticosteroids should be considered, especially in the elderly, as many studies have shown accelerated rates of cutaneous healing and alleviation of acute pain. Torrens et $a l^{10}$ showed that there was a wide variation in both preadmission and inpatient treatment. They reported that $53.3 \%$ did not receive any anti-viral therapy before admission. It was found that general practitioners prescribed $5 \%$ idoxuridine topically in $15 \%$ of the cases despite multiple sources agreeing that there is no role for the use of topical antiviral drugs in the management of herpes zoster. Goh and $\mathrm{Khoo}^{11}$ confirmed that only 9\% of affected patients consulted their GP during the prodrome or on the day of skin eruptions. They concluded there was a need for patient education to identify prodrome and skin eruptions of herpes zoster so that early antiviral therapy can be given at the optimal time.

\section{Follow up}

These patients need following up in the community, and there should be continuing audit of the disease to try to minimise further morbidity. This is particularly important with respect to post-herpetic neuralgia and ocular complications. Review of the patient after four to six weeks, or earlier if the pain is poorly controlled, allows prompt treatment with neurotropic agents ${ }^{4}$ (for example, gabapentin, carbamazepine, or amitriptyline). Acute retinal necrosis can occur in immunocompetent patients. Visual changes begin weeks or months after the resolution of herpes-zoster as a result of haematogenous spread. Herpes-zoster affecting any dermatome could therefore lead to ocular damage, and this could be minimised by early ophthalmic review and the use of oral corticosteroids. ${ }^{12}$ Review of the patient could also help to ensure that cutaneous lesions are kept clean and dry, to reduce the risk of bacterial superinfection.

In summary, failure of early diagnosis by junior staff in this case led to delayed implementation of antiviral therapy in a patient with herpes zoster affecting the trigeminal nerve. There was no supporting evidence to suggest bacterial superinfection yet the patient received multiple antibiotics. It is questionable whether steroid therapy or an alternative antiviral agent to aciclovir could also have been useful in speeding the patient's recovery. A mucus discharge was noted from the left eye but no other signs of involvement of the ophthalmic branch of trigeminal nerve. As a precautionary measure, and in the light of what is known about ocular spread, it might have been prudent to have sought an ophthalmic review at some stage.

Correspondence to: Dr Robert Goddard, General Surgery, Queen Elizabeth and Queen Mary Hospitals, East Kent Hospitals NHS Trust; goddard1998@aol.com

Accepted for publication 12 August 2003

Patient consent was obtained

\section{REFERENCES}

1 Bajwa ZH, Ho CC. Herpetic neuralgia: use of combination therapy for pain relief in acute and chronic herpes zoster. Geriatrics 2001;56:18-24.

2 Cunningham A, Dworkin R. The management of post-herpetic neuralgia. BMJ 2000;321:778-9.

3 Torrens J, Nathwani D, MacDonald T, et al. Acute Herpes zoster in Tayside: demographic and treatment details in immunocompetent patients 1989-1992. $J$ Infect 1998;36:209-14.

4 Edmunds WJ, Brisson M, Rose JD, et al. The epidemiology of herpes zoster and potential cost-effectiveness of vaccination in England and Wales. Vaccine 2001; 19:3076-90.

5 Brisson M, Edmunds WJ, Gay NJ, et al. Analysis of varicella vaccine breakthrough rates: implications for the effectiveness of immunisation programmes. Vaccine 2000;18:2775-8.

6 Wharton M. The epidemiology of varicella-zoster virus infections. Infect Dis Clin North Am 1996;10:571-81. 
7 Trannoy E, Berger R, Hollander G, et al. Vaccination of immunocompetent elderly subjects with a live attenuated Oka strain of varicella zoster virus: a randomized, controlled, dose-response trial. Vaccine 2000;18:1700-6.

$8 \mathrm{Goh}$ CL, Khoo L. A retrospective study of the clinical presentation and outcome of herpes zoster in a tertiary dermatology outpatient referral clinic. Int J Dermatol 1997;36:667-72.
9 Gnann JW, Whitley RJ. Clinical practice. Herpes zoster. N Engl J Med 2002;347:340-6.

10 Gnann JW. Varicella-zoster virus: atypical presentations and unusual complications. J Infect Dis 2002;186(suppl 1):S91-8.

11 Stankus SJ, et al. Management of herpes zoster (shingles) and postherpetic neuralgia. Am Fam Physician 2000;1:2437-44, 2447-8.

\section{A role for video assisted thoracoscopy in stable penetrating chest trauma}

R Hanvesakul, A Momin, M J Gee, M T Marrinan

Emerg Med J 2005;22:386-387. doi: 10.1136/emj.2003.014076

A 40 year old woman presented to a district general hospital following a stabbing to the back of her chest with a large bread knife. She arrived with the knife still in situ (fig 1). On initial assessment she was found to be haemodynamically stable with no other injuries. Chest $\mathrm{x}$ ray revealed a knife and a small right pneumothorax (fig 2). An intercostal chest drain was inserted and $450 \mathrm{ml}$ of blood drained. As she remained haemodynamically stable she was transferred to the regional cardiothoracic centre for further management. The knife was left in situ and she was managed prone. On arrival in the cardiothoracic centre she was taken to theatre and anaesthetised on her side. She then underwent a video assisted thoracoscopy (VAT) to visualise the extent of internal chest injuries and to see the entry point into the chest cavity. Fortunately the knife had entered her chest parallel to the chest wall beneath the scapula and had caused minimal injury to the underlying lung (pulmonary contusion only) without damaging the great vessels. It was then withdrawn under direct vision, with no bleeding from the chest entry site. A further chest drain was inserted and she made an uneventful recovery from her surgery.

VAT can be used for repairs of pulmonary and diaphragmatic lacerations, removal of foreign bodies and haematoma, and haemostasis. ${ }^{3}$ The limited literature on use of VAT in this

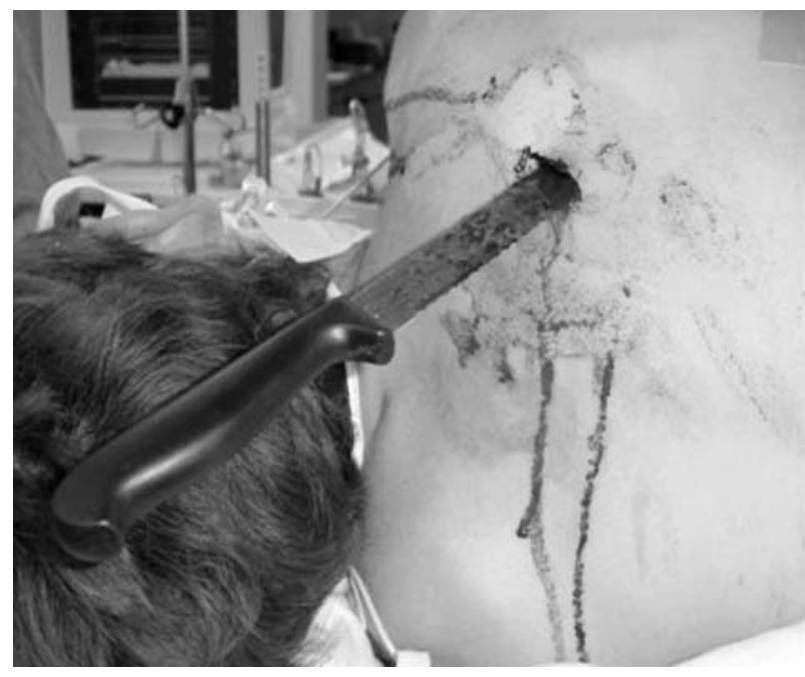

Figure 1 Patient being anaesthetised for video assisted thoracoscopy (VAT) procedure. Note knife in back (nine serrations length measuring $9 \mathrm{~cm}$ of the bread knife was visualised in the pleural cavity using VAT).

\section{Box 1 Key points for penetrating chest trauma}

- Adequate assessment and resuscitation

- Leave any weapons in situ until definitive surgery is available

- Minimally invasive surgery, such as VAT, allows full assessment and management without resorting to major thoracotomy in stable trauma patients with its associated decrease morbidity and shorter hospital stay. ${ }^{1-3}$

setting reflects the low incidence of penetrating trauma in the UK. Retrospective studies confirm its safe use in stable patients and low rate of conversion to open thoracotomy. ${ }^{23}$ Nevertheless, VAT should be performed in a well-equipped cardiothoracic theatre where open thoracotomy sets and experienced theatre staff are available. In this case, the patient was appropriately positioned in the left lateral position and the facilities for open thoracotomy available.

Abbreviations: VAT, video assisted thoracoscopy

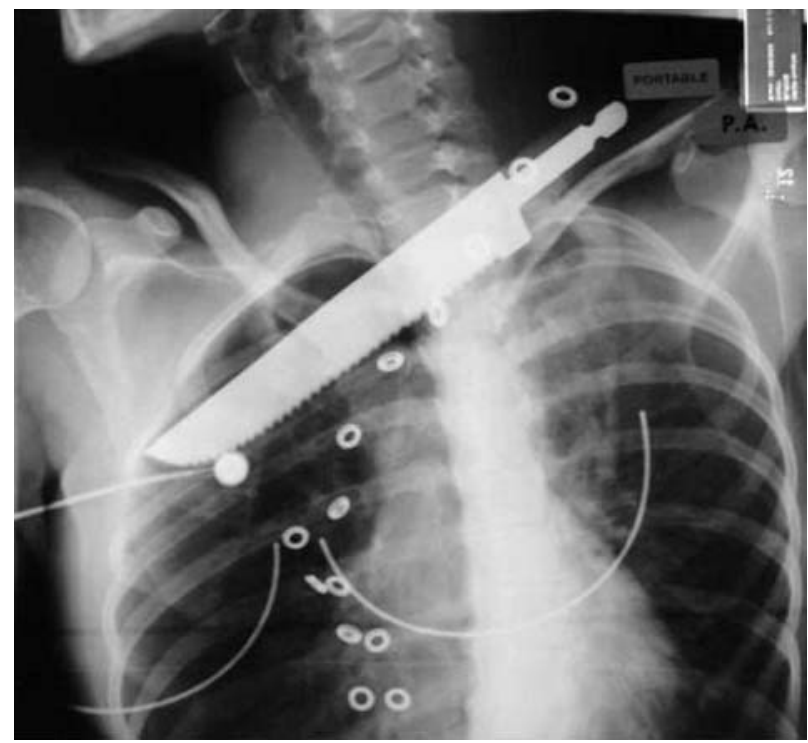

Figure 2 Chest $x$ ray demonstrating knife in situ. 
VAT could therefore have been immediately converted to open thoracotomy in event of difficulties.

\author{
Authors' affiliations \\ R Hanvesakul, A Momin, M J Gee, M T Marrinan, Department of \\ Cardiothoracic Surgery, King's College Hospital, Denmark Hill, London, \\ SE5 9RS, UK \\ Funding: none \\ Competing interests: none declared
}

Correspondence to: Rajesh Hanvesakul, Department of Cardiothoracic Surgery, King's College Hospital, Denmark Hill, London, SE5 9RS, UK; rhanvesakul@doctors.org.uk
Received 29 December 2003

In revised form 22 February 2004

Accepted for publication 8 April 2004

Patient consent was obtained

\section{REFERENCES}

1 Abolhoda A, Livingston DH, Donahoo JS, et al. Diagnostic and therapeutic video assisted thoracic surgery (VATS) following chest trauma. Eur J Cardiothorac Surg 1997; 12(3):356-60.

2 Liu DW, Liu HP, Lin PJ, et al. Video-assisted thoracic surgery in treatment of chest trauma. J Trauma 1997;42(4):670-4.

3 Pons F, Lang-Lazdunski L, de Kerangal X, et al. The role of videothoracoscopy in management of pre-cordial thoracic penetrating injuries. Eur J Cardiothorac Surg 2002;22(1):7-12.

\title{
Spontaneous spinal epidural haematoma: a therapeutical challenge?
}

\author{
Report of an unusual case
}

\section{J Schröder, S Palkovic, H Wassmann}

Emerg Med J 2005;22:387-388. doi: 10.1136/emj.2003.014027

We report the conservative treatment of a spontaneous spinal epidural haematoma attending with acute extensive neurological deficits, which resolved spontaneously. Spontaneous remission of spontaneous spinal epidural haematoma with severe neurological deficit is rare in the literature. An 80 year old man was admitted to our hospital presenting sciatica followed by rapid development of paraparesis and cauda equina syndrome, which represents a neurosurgical emergency. Magnetic resonance imaging revealed a multilevel epidural haematoma from L1 to L5. During the initial diagnostic procedure the symptoms started to decline unexpectedly, so the surgical intervention could be withdrawn. Twenty four hours after admission the patient was almost free of symptoms, mobile, and continent. Awareness and high index of suspicion, and a willingness to seek the prompt help of the imaging department, are crucial to successful management before the opportunity to treat is lost.

$\mathrm{S}$ pinal epidural haematomas (SEH) are infrequent events caused mainly either by trauma or iatrogenic following invasive spinal procedures (lumbar puncture, surgery, or peridural anaesthesia). The spontaneous spinal epidural haematoma (SSEH) is a rare entity requiring an emergency intervention in most cases. The incidence is estimated at about two to six cases per year. ${ }^{1}$ The posterior internal vertebral venous plexus seems to play an important role in the development of the SSEH; ${ }^{2}$ the role of vascular anomalies is overestimated. Coagulopathy may facilitate the development of haematoma but is not the cause of SSEH. The relation between hypertension and SSEH is not proven. ${ }^{2}$

The clinical diagnosis is difficult despite the somewhat characteristic presentation with rapid onset of symptoms, such as sudden pain and rapidly progressing neurological deficits. ${ }^{3}$ We describe the management of the case of a rather extended SSEH with unexpected outcome.

\section{CASE REPORT}

An 80 year old man was admitted to our hospital presenting an acute onset of sciatica with rapid progress to high grade paraparesis and a cauda equina syndrome within the next 30 minutes. He arrived at the hospital 3 hours after onset of the first symptoms. The previous history was non-specific with the exception of medication treated high blood pressure. He has never received anticoagulants. On admission the general status was without pathological findings except from a blood pressure of $230 / 130 \mathrm{mmHg}$. He presented a weakness of the iliopsoas muscles (3/4), quadriceps (3/5), tibialis anterior and extensor hallucis longus (3/5 right, $4 / 5$ left), and gastrocnemius $(4 / 5)$ with a sensory disturbance from L4 level. The

Abbreviations: $M R I$, magnetic resonance imaging; $\mathrm{SEH}$, spinal epidural haematoma; SSEH, spontaneous spinal epidural haematoma
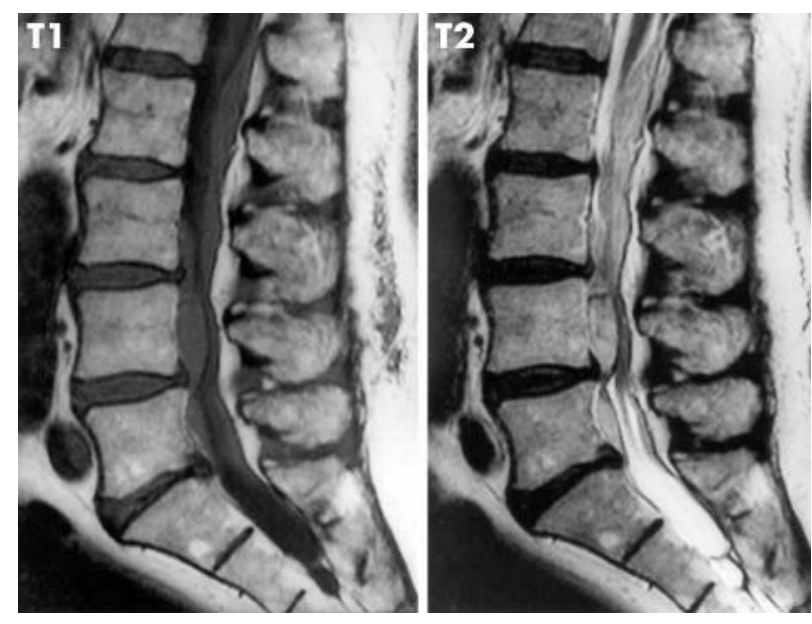

Figure 1 MRI scan on admission showing compression of the cauda equina by a spontaneous spinal epidural haematoma (left $\mathrm{Tl}$ weighted, right T2 weighted). 


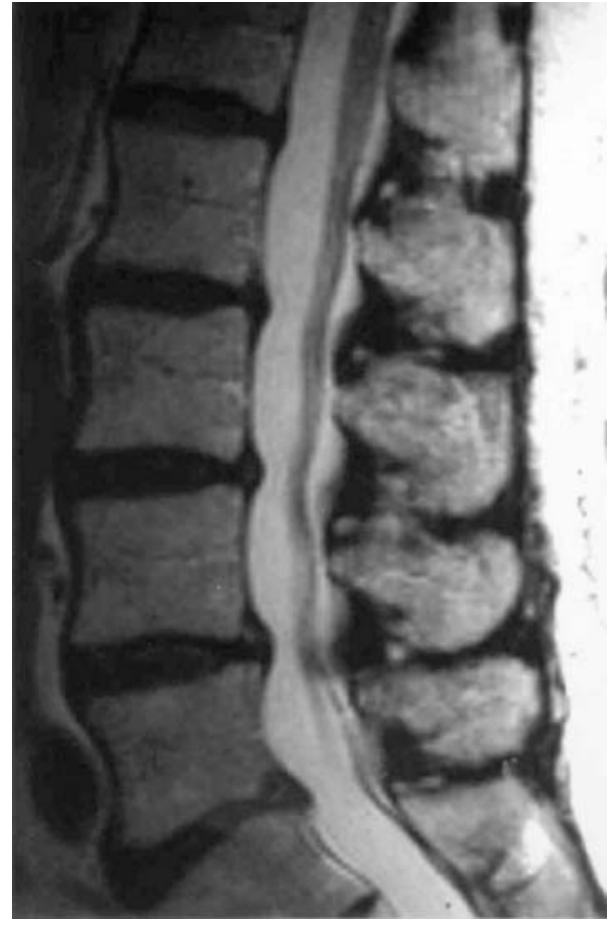

Figure 2 MRI follow up after 5 months showing complete resolution of the haematoma. Reproduced with patient's permission.

anal sphincter tonus was weakened, with disturbed anal sensation and urinary bladder retention of $300 \mathrm{ml}$ after catheterisation. Patellar and Achilles tendon reflexes were lost. Magnetic resonance imaging (MRI) revealed an epidural haematoma from the inferior margin Ll posteriorly down to L5 anteriorly in the spinal canal (fig 1). During the initial diagnostic procedure, approximately 4 hours after onset, the symptoms started to decline so that the already planned surgical intervention could be cancelled. After 6 hours the sensory disturbances had disappeared. Already 24 hours after admission the patient was almost free of symptoms, mobile, and continent. He was discharged after the next day. The further course was uneventful. We could follow up the patient within 5 months free of complaints. Besides bilateral absent Achilles tendon reflexes, he was without any neurological deficits. The MRI showed a complete resolution of the spinal haematoma (fig 2).

\section{DISCUSSION}

A SEH causing severe neurological deficits is considered a medical emergency. MRI is the method of choice for establishing the diagnosis ${ }^{4}$ and facilitates the differential diagnosis between epidural haematoma, disc herniation, epidural tumour, or infection. Follow up MRI is needed to follow the evolution of a presumed SEH.

The posterior internal vertebral venous plexus seems to play an important role in the aetiology of the SSEH. ${ }^{2}$ In our case, the main part of the haematoma at L4 level is located anteriorly. However, the only obvious medical problem in our case-that is, arterial hypertension-appears to be unrelated to the SSEH. ${ }^{2}$
Early surgical decompression was formerly believed to be the only treatment method, ${ }^{156}$ with the timing of surgery determining the quality of the result. ${ }^{4}$ Other authors ${ }^{7}$ reported an improvement even after delayed surgery. Conservative treatment was reserved for cases with only minimal neurological deficits.

In the recent literature a number of cases with spontaneous recovery have been presented.$^{8-10}$ Conservative management of the SSEH may be appropriate if early and substantial neurological recovery is noticed, such as in our case.

There have been a number of reports ${ }^{8-10}$ of spontaneous and complete recovery of SEHs. The incidence is possibly higher then previously thought, because more cases with less severe deficits have probably been misdiagnosed as transient low back pain. The broad availability of MRI facilities will discover increasing numbers of SEH; nevertheless, the neurological status will continue to dictate whether management is surgical or conservative.

Although SEH causing compression of neural structures is considered usually for emergency decompression, astonishingly there are some cases with a good clinical regression of restricted function even with severe initial neurological impairment, which can be handled non-surgically.

\section{Authors' affiliations}

J Schröder, S Palkovic, H Wassmann, Department of Neurosurgery, University of Münster, D-48129 Münster, Germany

Funding: none

Competing interests: none declared

Correspondence to: J Schröder, Department of Neurosurgery, University of Münster, D-48129 Münster, Germany; j.schroder@web.de

Received 23 December 2003

In revised form 16 February 2004

Accepted for publication 16 February 2004

Patient consent was obtained

\section{REFERENCES}

1 Jamioom ZA. Acute spontaneous spinal epidural hematoma: the influence of magnetic resonance imaging on diagnosis and treatment. Surg Neurol 1996;46:345-9.

2 Groen RJ, Ponssen $\mathrm{H}$. The spontaneous spinal epidural hematoma. A study of the etiology. J Neurol Sci 1990;98:121-38.

3 Rechtine GR, Bolesta MJ, Chrin AM, et al. Spontaneous resolution of symptomatic post-traumatic cervical epidural hematoma. A case report. J Bone Joint Surg Am 2001;83-A:255-58.

4 Lonjon MM, Paquis $P$, Chanalet $S$, et al. Nontraumatic spinal epidural hematoma: report of four cases and review of the literature. Neurosurgery 1997;41:483-6.

5 Yettou H, Vinikoff L, Marchal JC, et al. [Spontaneous spinal epidural hematoma. Apropos of 2 new cases]. [French] Neuro-Chirurgie 1995:41:58-61.

6 Alexiadou-Rudolf C, Ernestus RI, Nanassis K, et al. Acute nontraumatic spinal epidural hematomas. An important differential diagnosis in spinal emergencies. Spine 1998;23:1810-13.

7 Buhl R, Kretschmer H. [Spontaneous spinal epidural hematoma: good outcome after delayed treatment]. [German] Zentralb/ Neurochir 1998;59:109-12.

8 Wagner S, Forsting M, Hacke W. Spontaneous resolution of a large spinal epidural hematoma: case report. Neurosurgery 1996;38:816-18.

9 Clarke DB, Bertrand G, Tampieri D. Spontaneous spinal epidural hematoma causing paraplegia: resolution and recovery without surgical decompression. Neurosurgery 1992;30:108-11.

10 Silber SH. Complete nonsurgical resolution of a spontaneous spinal epidural hematoma. Am J Emergy Med 1996;14:391-3. 


\section{Acute cyanide poisoning by subcutaneous injection I Prieto, I Pujol, C Santiuste, R Poyo-Guerrero, A Diego}

\begin{abstract}
A 30 year old woman with a history of depression and previous suicide attempts was brought to the emergency department in coma. She had injected herself with cyanide subcutaneously and had severe metabolic acidosis. She underwent sustained haemodialysis in the intensive care unit (ICU) before laboratory confirmation of cyanide poisoning. The serum cyanide concentration was $4.6 \mu \mathrm{g} / \mathrm{ml}$. After 48 hours the patient, now asymptomatic, was discharged from the ICU.
\end{abstract}

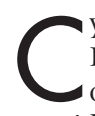
yanide poisoning can present in a wide variety of forms. Inhalation and ingestion are the most frequent routes of administration. ${ }^{1}$ The natural history of severe acute cyanide poisoning is rapid progression to coma, severe lactic acidosis, respiratory failure, shock, and death. ${ }^{2}$ Here we present a unique case of severe acute cyanide poisoning following subcutaneous injection.

\section{CASE REPORT}

A 30 year old woman with history of previous suicide attempts was found in her house in a state of coma (Glasgow Coma Scale 3). There were four hypodermic syringes near her, of which two were full. On admission to the emergency department the patient was still in coma with reactive mydriasis. She had severe hypotension and required endotracheal intubation as well as fluids and vasoactive drugs, dopamine $5 \mu \mathrm{g} / \mathrm{kg}$ per min and noradrenaline (norepinephrine) $0.4 \mu \mathrm{g} / \mathrm{kg}$ per min. Physical examination revealed six macular, erythematous lesions, $1-3 \mathrm{~cm}$ in diameter, on her left arm and hemithorax. A few hours later the lesions developed into blisters with epidermal necrosis (fig l).

Laboratory analysis revealed severe metabolic acidosis $(\mathrm{pH}$ 6.74; $\mathrm{HCO}_{3}{ }^{-} 5 \mathrm{mmol} / \mathrm{l}$ ) with high levels of lactic acid ( $19.3 \mathrm{mmol} / \mathrm{l})$, moderate leucocytosis $\left(21.10^{3} \mathrm{cells} / \mathrm{ml}\right)$, and altered prothrombin activity $(47 \%)$. The anion gap was $33 \mathrm{mmol} / \mathrm{l}$. Urinalysis, electrocardiogram (ECG) and chest radiographs were normal. No evidence of salicylates, benzodiazepines, antidepressants, opiates, and amphetamines was found. A brain computed tomography (CT) scan ruled out organic damage.

She was given sodium bicarbonate $(250 \mathrm{mEq})$ intravenously. Her venous blood gas analysis showed pH 7.134; $\mathrm{PCO}_{2}$ $19.4 \mathrm{~mm} \mathrm{Hg}$; and $\mathrm{HCO}_{3}{ }^{-} 6.6 \mathrm{mmol} / \mathrm{l}$. Four hour haemodialysis was perfomed, and during this time it was possible to stop the dopamine and noradrenaline. At the end of the procedure the venous blood gas analysis was as follows: $\mathrm{pH}$ 7.303; $\mathrm{PCO}_{2} 32.8 \mathrm{~mm} \mathrm{Hg}$; and $\mathrm{HCO}_{3}{ }^{-} 16.4 \mathrm{mmol} / \mathrm{l}$. A few hours later her consciousness level returned to normal (Glasgow Coma Scale 15). Venous blood gases and lactic acid levels returned to normal the day after she was admitted. The patient was conscious and cooperative, and had no neurological sequelae. She remembered that she had bought the cyanide from a specialist shop selling biochemistry products. The blood sample which was taken before haemodialysis had a cyanide ion concentration of $4.6 \mu \mathrm{g} / \mathrm{ml}$. Analysis of the liquid in the syringes taken from her house revealed a cyanide ion concentration of $1.53 \mathrm{mg} / \mathrm{ml}$. The cyanide was dissolved in ethyl alcohol. After 48 hours following admission the asymptomatic patient was discharged from the ICU and admitted to the psychiatric service.

\section{DISCUSSION}

The use of cyanide for committing suicide has been reported time and again since antiquity. In the past it was easy to obtain sodium or potassium cyanide and the effects were generally known. Cyanide poisoning causes histotoxic hypoxia-that is, there is inhibition of mitochondrial cytochrome oxidase with disruption of the ability of cells to use oxygen. ${ }^{3}$ As a result cellular hypoxia ensues with a large increase in lactic acid production, and consequently there is metabolic acidosis with an elevated anion gap. The tissues most dependent on oxidative phosphorylation-the heart and brain-are the most severely and quickly affected. Thus the initial symptoms are a manifestation of functional deficit of the central nervous system. Inhibition of the respiratory centre leads to transitory hyperventilation followed by respiratory depression, respiratory failure, coma, and death. Myocardial depression causes further hypoxia with decreased cardiac output and shock.

The most frequent routes of administration of cyanide are inhalation and ingestion. Dermal exposure is rare, with only two cases reported in the literature. In one, cyanide poisoning was secondary to burns by cyanide salts, ${ }^{4}$ and in the other, the cause was immersion in cyanide solution. ${ }^{5}$ No case of cyanide poisoning after subcutaneous administration has been described.

Although supportive measures may sometimes prove satisfactory, patients treated with specific antidotes, sodium nitrite, sodium thiosulfate, dimethylaminophenol, and hydroxycobalamin together with supportive therapy have survived despite higher blood cyanide levels, have awoken sooner from coma, and shown more rapid correction of acidosis. $^{6}$

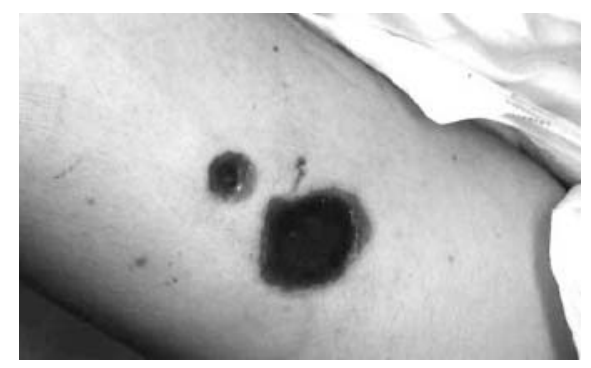

Figure 1 Two (of six) macular, erythematous lesions on the patient's left arm three hours after she was admitted to the emergency department. 
Extracorporeal elimination techniques are not standard therapy for severe acute cyanide poisoning even though the cyanide ion is a small charged molecule which is potentially dialysable. Only one case treated with supportive therapy, antidotes, and haemodialysis has been reported. ${ }^{7}$ Our patient underwent a four hour haemodialysis session for severe and refractory metabolic acidosis ( $\mathrm{pH}$ 6.74) secondary to an unknown toxic agent. Although the blood concentration of cyanide ion was not so high, our patient had severe symptoms and signs (coma, shock, and severe metabolic acidosis), which disappeared after haemodialysis. We did not use any specific cyanide antidotes because we were not aware of the nature of the toxic agent at that time. No report has been published about patients with severe cyanide poisoning (whole blood levels higher than $2.3 \mu \mathrm{g} / \mathrm{ml}$ ) who were given intensive empirical care without specific antidotes and yet survived. ${ }^{8}$

In summary, we have reported a case of acute cyanide poisoning following subcutaneous injection-a novel route of administration of cyanide-treated with only haemodialysis. Although haemodialysis is not a specific treatment for cyanide poisoning, it may be a suitable adjunctive treatment to antidotes and other supportive measures.
Authors' affiliations

I Prieto, I Pujol, C Santiuste, R Poyo-Guerrero, A Diego, Ramon y Cajal Hospital, Madrid, Spain

Correspondence to: I Prieto, Ramon y Cajal Hospital, Madrid, Spain; iprieto.hrc@salud.madrid.org

Accepted for publication 1 June 2004

Patient consent was obtained

\section{REFERENCES}

1 Vennesland B, Conne E, Knowles C, et al. Cyanide in biology. London: Academic Press, 1981:16.

2 Hall AH, Rumack BH. Clinical toxicology of cyanide. Ann Emerg Med 1986; 15: 1067.

3 Vogel SN, Sultan TR, Ten Eyck RP. Cyanide poisoning. Clin Toxicol 1981;18:367.

4 Bourrelier J, Paulet G. [Hydrocyanic poisoning following severe burns by fused sodium cyanate. 3 cases treated with EDTACO2] [Article in French] Presse Med 1971;22:1013-14

5 Dodds C, McKnight C. Cyanide toxicity after immersion and the hazards of dicobalt edetate. Br Med J (Clin Res Ed) 1985;291:785.

6 Feihl F, Domenighetti G, Perret C. Intoxication massive au cyanure avec evolution favorable. Schweiz Med Wochenschr 1982;112:1280.

7 Wesson DE, Foley R, Sabatini S, et al. Treatment of acute cyanide intoxication with hemodialysis. Am J Nephrol 1985:5:121.

8 Hall AH, Doutre WH, Ludden T, et al. Nitrite thiosulfate treated acute cyanide poisoning: estimated kinetics after antidote. Clin Toxicol 1987;25:121. 